\title{
EPSRC Multimedia and Networking Applications Research Programme
}

\author{
Michael Wilson
}

\section{The EPSRC has launched a managed programme of research into multimedia and networking applications. Industrial involvement is solicited in order to ensure the applicability of the research, and the adoption of results.}

The Internet, World Wide Web (WWW) and Multimedia have become buzzwords in the last few years not only for computer professionals, but even for children's television presenters. Software tools are now available to support multimedia publishing on CDROM which are being used not only by aggressive IT companies but also established publishers who can revitalize their existing lists of back titles. More immediate availability of information is provided by publishing it over the WWW in the form of navigable hypermedia incorporating text and images. The initial developers of the software tools for publishing multimedia CD-ROMs and accessing the WWW have now floated companies and created markets for their products into which established software houses are moving by incorporating these innovations into their existing product lines.

Despite the success of these innovations they do not satisfy everybody's information needs as can be seen from the list of outstanding research issues in the sidebar. Multimedia systems and techniques are advancing rapidly and, coupled with developments in multiservice networking, offer considerable scope for innovative product and service development for wide ranging applications. The implications for potential wealth creation and enhanced quality of life are very substantial; the challenge is to ensure that the UK benefits appropriately from these opportunities and advances (at least in line with international competitors). In 1992, a report by the Economic Strategy Institute in Washington DC. indicated that the accelerated introduction of high-speed communications could boost US economic growth by 4 to $6 \%$ over the next 15 years. Similar UK growth is possible through the application of multimedia and networking technology to manufacturing, publishing, health care, education and the entertainment and leisure industries.

The actions required to produce products which will stimulate such growth range from basic research to full product development and adoption. There is no strict border line between basic research of an exploratory nature, pre-competitive R\&D which has a clear vision of the application and competitive $R \& D$ which is clearly focused on commercial products. In principle, competitive R\&D is undertaken within commercial organisations and draws on internal funding whilepre-competitive $R \& D$ is performed by consortia of companies and research organisations into multimedia products is supported under the European Commission's IT and Telematics programmes whereas research into advanced communications is supported by the European Commission's ACTS programme. These developments are supported at the European level to ensure that the key European infrastructure and service developments are technically compatible, operationally 
interconnected and synchronous in time. The economic and employment advantages of this investment will not berealised otherwise. In contrast, by applying the principle of subsidiarity basic research is supported at the national level. As part of its IT and Computer Science programme, the Engineering and Physical Sciences Research Council (EPSRC) is supporting a managed programme of UK basic research in the area of multimedia and networking applications (MNA).

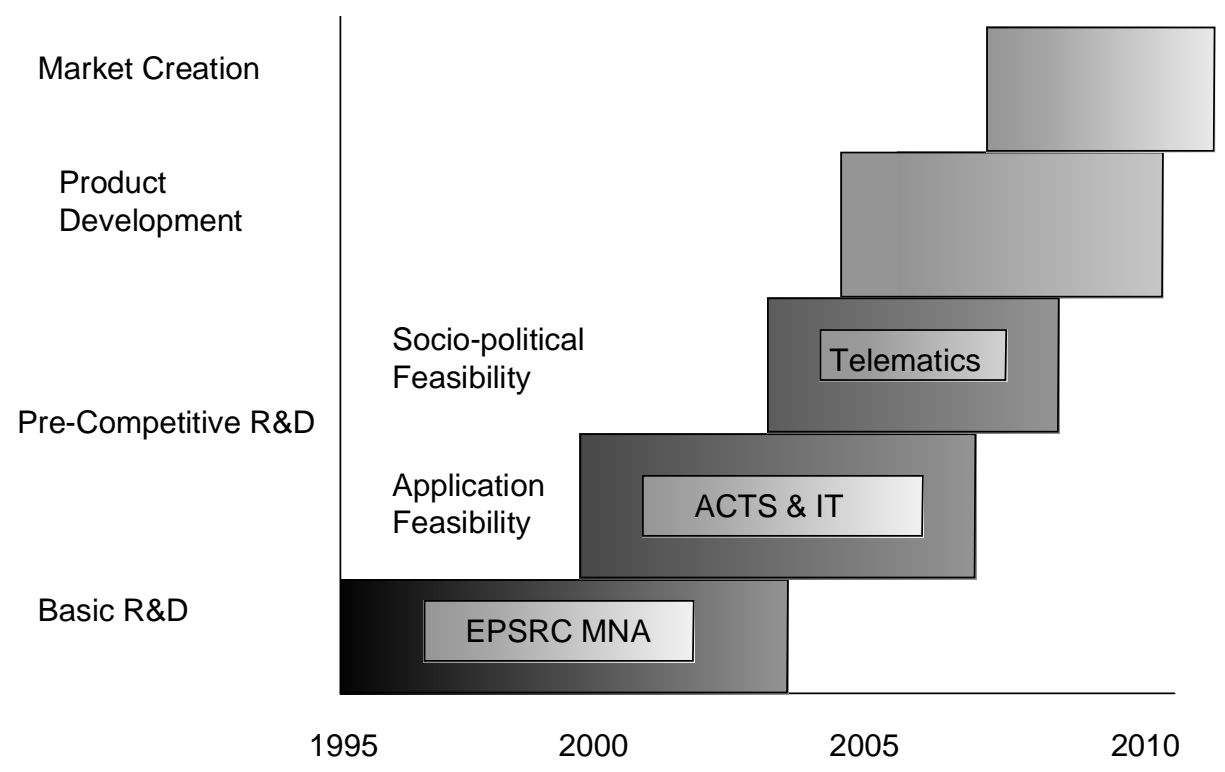

Figure 1 : Stages leading to wealth creation from MNA technology

The MNA programme started in 1995 with the first of five intended annual calls for proposals against a total EPSRC budget of five and a half million pounds. Each call is open to proposals addressing the full range of research issues covered by the overall programme, but each call is also focused on a specific topic. The focus in the first call in June 1995 was the integration of component services to form value added services and distributed multimedia. Seventy-two proposals were received for the first call, of which fourteen were selected for funding starting in late 1995. The focus of the second call is the mobility of both computers and users, and it is intended that at least half the projects funded will address this topic. The closing date for receipt of proposals in response to the second call will be 13 May 1996. It is planned that the third call towards the end of 1996 will focus on human factors issues in multimedia and networking applications. The topics for the fourth and fifth calls expected in succeeding years have not yet been chosen, but they are expected to build on the technological results of earlier projects.

A number of compelling reasons lie behind the choice of mobility as the theme for the second call of the MNA programme. At the forefront of these are the themes of information society and virtual organisations, the first of which is the subject of key 
initiatives by the European Commission and more recently by the UK Government, while the second is acquiring an inevitable momentum as organisations 'downsize' or fform using more dynamic forms of staffing. In the case of the information society, government recognises the importance of exploring new markets, products and services based on access to information wherever and whenever it is needed.

Technology, including portable and multimedia workstations, and wireless and fixed communications, is now at the point of being able to offer a costeffective basis for the mobile computing user; yet, as usual, technology is ahead of the systems and application software needed to underpin the reality of ubiquitous mobile access. It is therefore timely to introduce mobility as the special focus of this second call.

\section{Applicability and Industrial Involvement}

The aim of this programme is the development of generic solutions which will address the needs of the user community. This will be achieved through the support of high quality, relevant research, conducted either in collaboration with industry or solely within academia. Typical industrial partners on collaborative proposals might be organisations which intend to develop and/or exploit the results of the research commercially or end-users who could provide real applications or demonstrations/trials; proposals involving both categories of industrial partners will be given priority.

It is intended that approximately three-quarters of the projects supported will be collaborative in nature, but all projects funded under the MNA programme are expected to have a strong applications pull. This pull does not require that projects produce application demonstrators; indeed the demands of these are beyond the scope of the programme. To show an applications pull, projects must be able to provide a scenario of application use incorporating the technology or service which is the topic of the proposal. It is expected that both the requirements placed on the technology by the application, and the constraints placed on the application by the technology would be clarified during a project, and these would guide the research.

End users who could collaborate in research projects would have identified "a problem" and act as "the problem owner" to drive the research. Such problems provide specific questions which, when resolved, will have a beneficial effect in the area concerned. However, such problems must be shown to be amenable to a technological solutionand not an organisational or political one. The European Commission's Telematics programme has been established to support projects which address organisational or political problems preventing the uptake of information technology at a European level.

\section{Conclusion}

The scenario being used to direct European research and development whereby Europe will advance from its present position to an advanced communications environment in the year 2010 is segmented into four periods of pre-competitive R\&D : 
1990-1995 The development of ISDN

1995-2000 The implementation of IBC

2000-2005 The integration of intelligence and mobility

2005-2010 The transparent network

The MNA programme is designed to establish the UK to be in a position to provide the technological solutions to drive the third and fourth of these periods. The programme will support research in institutions of higher education, but there are three clear roles for industrial collaboration. The first two are to provide applications pull, and user problems to be solved as described above. The third is to identify relevant research results and carry them into pre-competitive $\mathrm{R} \& \mathrm{D}$, and eventually into products in order to generate wealth.

For further information on the MNA programme please contact the programme coordinator Dr Michael Wilson at the Rutherford Appleton Laboratory (telephone: 01235 446619; e-mail: M.Wilson@rl.ac uk ; fax: 0123 445831) or access the WWW page for the programme which includes a full call for proposals and details of the proposal submission procedure at http://www.cis.rl.ac.uk/clubs/MNA/. 


\section{Multimedia and Networking Applications Programme Research Issues}

Systems Integration

- Tools and techniques needed for constructing and dynamically reconfiguring value added services and applications from existing components and lower level services.

- Specification of required service in terms of service types, behavior, quality etc.

- Use of directory services or trading concepts for locating services.

- Issues of fault tolerance, security, accounting, quality of service and management, which have to scale to cope with large, inter-organisational systems and how these issues interact within different underlying services.

$\underline{\text { Network and Mobility Issues for Multimedia }}$

- Inter-networking of fixed and mobile networks, including resource allocation issues, for multimedia traffic.

- Traffic monitoring and control mechanisms to support the maintenance of quality of service contracts.

- Group support for multimedia communications in both mobile and fixed networks.

- Naming, locating and load balancing techniques for mobile clients or servers.

\section{Distributed Multimedia Services}

- How to provide global services and resources across multiple networks.

- Multimedia teleservices including provision for groupbased applications and synchronisation services.

- Distributed multimedia databases- how to describe, store and retrieve multimedia information in a database.

- Video on demand - data location, replication and load balancing issues.

- Licensing and copyright control techniques for reusing multimedia information. 
Human Factors Issues

- Design methods and tool support for multimedia human interface.

- Applicability and effectiveness of using different media to communicate across networks including virtual reality, live video, onthe-fly animation etc..

- Techniques for creating and interacting with virtual organisations.

$\underline{\text { Economic Issues }}$

- Comparative costs (and economic benefits) of MNA compared with alternative solutions. 